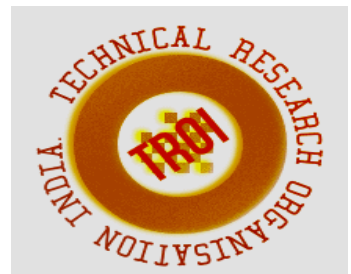

\title{
A NOVEL AC-DC POWER FLOW USING MATLAB/SIMULINK \\ ${ }^{1}$ Raghu K S, ${ }^{2}$ Sumanth G S, ${ }^{3}$ Maheshan C M \\ ${ }^{1,2} \mathrm{UG}$ scholar , ${ }^{3}$ Assistant Professor \\ Department of EE, UVCE, Bangalore, INDIA \\ 1'raghuvmc97@gmail.com, 로manthgs1998@gmail.com, ${ }^{3}$ maheshan.cm@gmail.com
}

\begin{abstract}
The demand for electricity is growing rapidly year by year with the increase in development of industries. Nevertheless, because of expense and option to proceed concerns it is not that much simple to utilize officially settled double circuit line to their full limit by consolidating these high voltage ac-conditioning lines with high voltage dc. Usage of transmission line near warm stacking and superimposed power will not bring on any insecurity. This paper demonstrates the likelihood of transformation of ac conditioning lines into joined substituting dc current instead of changing line conductor, line separators additionally tower structures, there will be considerable increment in power exchange limit. In this paper a novel method of AC-DC power flow analysis is presented.This method is implemented in MATLAB/Simulink.
\end{abstract}

Keywords: Zigzag Windings, Reactive Power, Zig-Zag transformer, Harmonics, Inverter

\section{I.INTRODUCTION}

In the ongoing years in industrialization the interest of electrical vitality has appeared relentless development in the meantime it is moving errand to fulfill the need as the worries like expense and option to proceed procrastinated development of extra transmission lines. The vast majority of the occasions control is accessible at remote areas and in view of uneven land surfaces of earth surfaces it is hard to include new lines so it is constantly gainful to utilize the current AC lines to their full limit this should be possible by new idea of superimposing DC on existing double circuit AC lines that is joining AC and DC on a similar line this kind of concurrent stream of AC and DC current won't influence the strength of the line and the power upgrade happens by $72.13 \%$.

The course of action of simultaneous AC-DC control transmission in the conveyance organize by overlaying DC control stream on the current AC lines. Usual dispersion systems line are devoted to the blend utility of AC and DC electrical power.[1] The AC line are the indistinguishable as regular AC appropriation arrange with the exception of from the Zig-Zag transformer is to evacuate transformer immersion by the stream of DC current. [2]Delta associated essential winding is utilized instead of Star associated transformers for reduce the harmonics on each side.

The DC control is embedded to the impartial terminal of the Zig-Zag associated winding. Each conductor of the appropriation line holds third piece of the DC current together with AC current. As resistance are identical in the three phase of Zig-Zag transformer and also of the line therefore dc current distributed equally in all the phases.[3]

Current induced on the second side is nell, when zero sequence or third harmonics current flows in zigzag windings.[4] Harmonics from the generator is reduced by delta connected primary windings so effects of harmonics on mixed AC-DC power transmission system on both the sides of the transformer is eradicated.

The objective of this paper is to perform a novel technique in AC-DC power flow using MATLAB/Simulink. 


\section{II.SIMULTANEOUS AC-DC POWER TRANSMISSION}

Figure1 demonstrates central structure of composite alternating current direct current by means of 2 circuit line figure indicates source as synchronous generator associated with generator transformer associated with an ac transport utilizing breaker at other side the zigzag transformers and rectifier are associated with accomplish adage of the paper to change existing alternating current line into composite line we are taking some piece of ac and changing over into dc by utilizing line commutated 12-pulse rectifier bridge and this direct current delivered by rectifier is added to neutral of secondary of transformer.[5] It will be reconverted again to alternate current at getting end with the assistance of 12 pulse inverter.

If in case the harmonics are present we are utilizing $\mathrm{Xd}$ which is of generally high value to chop down harmonics because of high estimation of $\mathrm{X}$ insignificant current through the ground get created due to nearness of these parts.

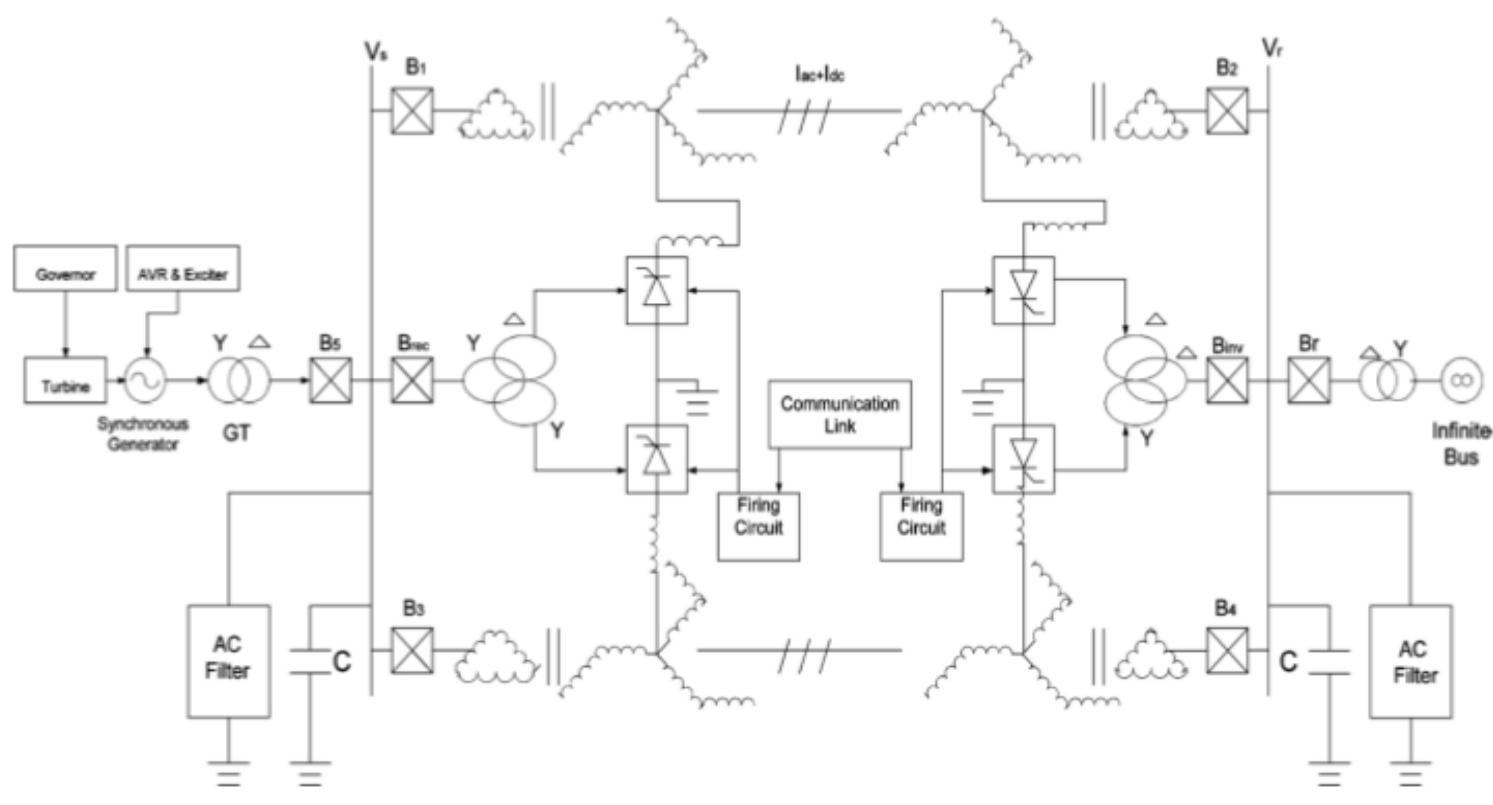

Fig1.Basic structure for composite AC-DC transmission

The methodology of solving the equations is by neglecting the resistive drops because of $\mathrm{dc}$ currents giving a set of algebraic expressions for ac voltage and current, and also for active and reactive powers in terms of $\mathrm{A}, \mathrm{B}, \mathrm{C}, \mathrm{D}$ parameters of each line. [6] These may be written as:

$\mathrm{Vs}=\mathrm{AV}_{\mathrm{R}}+\mathrm{BI}_{\mathrm{R}}$

Is $=\mathrm{CV}_{\mathrm{R}}+\mathrm{DI}_{\mathrm{R}}$

$\mathrm{Ps}+\mathrm{jQs}=-\mathrm{Vs}^{*} \mathrm{~V}_{\mathrm{R}} * / \mathrm{B}^{*}+\mathrm{D}^{*} \mathrm{~V}_{\mathrm{S}} 2 / \mathrm{B}^{*}(3)$

$\mathrm{P}_{\mathrm{R}}+\mathrm{jQ}_{\mathrm{R}}=\mathrm{Vs}^{*} \mathrm{~V}_{\mathrm{R}} / \mathrm{B}^{*}-\mathrm{A}^{*} \mathrm{~V}_{\mathrm{R}} 2 / \mathrm{B}^{*}$

By neglecting the resistive drops in zigzag transformers and the tie lines, the dc current Id, dc power Pdr and Pdi of each rectifier and inverter expressed.[7]
$\mathrm{Id}=[$ Vdro $\operatorname{Cos} \alpha-$ Vdio $\operatorname{Cos} \gamma] /[$ Rcr + Req Rci ] (5)

$\mathrm{Pdr}=\mathrm{Vdr} * \mathrm{Id}(6)$

Pdi $=$ Vdi $*$ Id (7)

Reactive powers needed by the converters are:

$\mathrm{Qdr}=\mathrm{Pdr} * \tan \theta \mathrm{r}(8)$

Qdi $=$ Pdi $* \tan \theta \mathrm{i}(9)$

$\cos \theta \mathrm{r}=[\cos \alpha+\cos (\alpha+\mu \mathrm{r})] / 2(10)$

$\cos \theta \mathrm{i}=[\cos \gamma+\cos (\gamma+\mu \mathrm{i})] / 2(11)$

$\mu \mathrm{i}$ is the commutation angles of inverter and $\mu \mathrm{r}$ is the of rectifier and the overall active and reactive powers at both the ends are:

Pst $=$ Ps + Pdr and Prt $=P_{R}+$ Pdi 
Qst = Qs + Qdr and Qrt $=\mathrm{Q}_{\mathrm{R}}+\mathrm{Qdi} \quad$ (13) $\quad \mathrm{P}_{\mathrm{L}}=\left(\mathrm{P}_{\mathrm{S}}+\mathrm{Pdr}\right)-\left(\mathrm{P}_{\mathrm{R}}+\mathrm{Pdi}\right)(14)$

Transmission loss for each line is:

\section{III.RESULTS}

TABLE I

COMPUTED RESULTS

\begin{tabular}{|c|c|c|c|c|c|}
\hline $\begin{array}{l}\text { Power Angle ( } \delta) \\
\text { Degrees }\end{array}$ & $30^{\circ}$ & $45^{\circ}$ & $60^{\circ}$ & $75^{0}$ & $80^{\circ}$ \\
\hline $\begin{array}{l}\text { ac } \quad \text { power(MW) } \\
=3 \mathrm{~V}_{\mathrm{a}}^{2} \operatorname{Sin} \delta_{2} / \mathrm{X}\end{array}$ & 290 & 410 & 502.61 & 560.6 & 571.55 \\
\hline $\begin{array}{l}\text { ac current } I_{a}(k A) \\
I_{a}=V(\operatorname{Sin} \delta / 2) / X\end{array}$ & 0.4166 & 0.6122 & 0.805 & 0.98 & 1.035 \\
\hline $\begin{array}{l}\text { de Current (kA) } \\
\mathrm{I}_{\mathrm{d}}= \\
\sqrt[3]{I_{t h}{ }^{2}-I_{a}{ }^{2}}\end{array}$ & 5.253 & 5.078 & 4.829 & 4.529 & 4.418 \\
\hline $\begin{array}{l}\text { De Power } P_{d c}=2 \text { Vdi } x \\
\text { Idi }(M W)\end{array}$ & 1684.8 & 1624.9 & 1545.5 & 1149.44 & 1413.76 \\
\hline $\begin{array}{l}\mathbf{P}_{\text {total }}=P_{\mathrm{ac}}+\mathbf{P}_{\mathrm{dc}} \\
(\mathrm{MW})\end{array}$ & 1971 & 2034 & 2048 & 2010 & 1985 \\
\hline
\end{tabular}

Fig 2

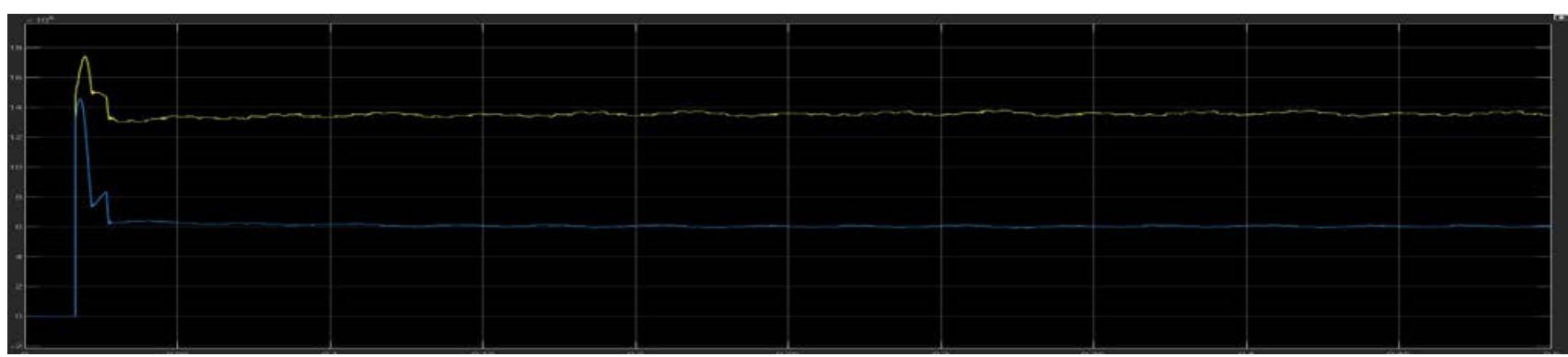

1) $P, Q$ sending end

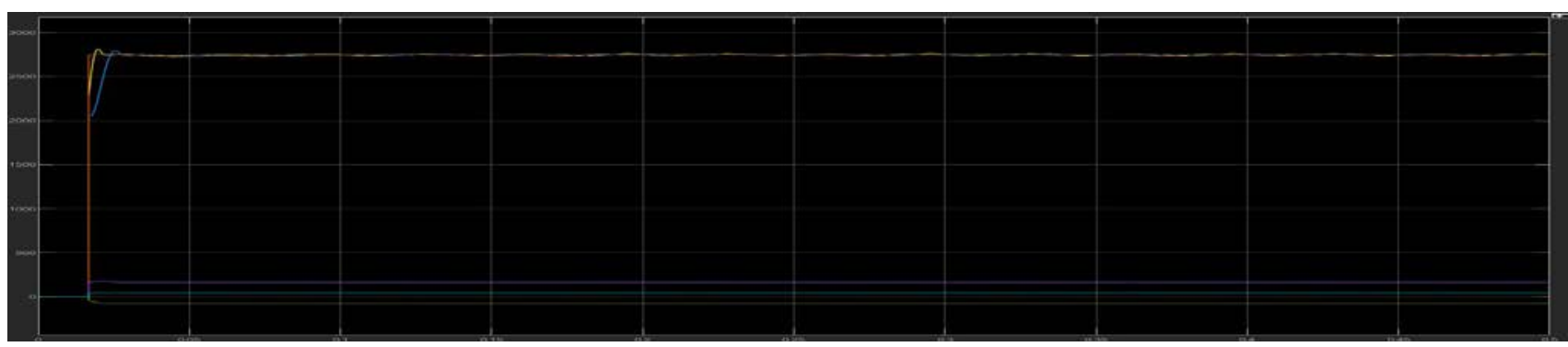

2) S ending end current

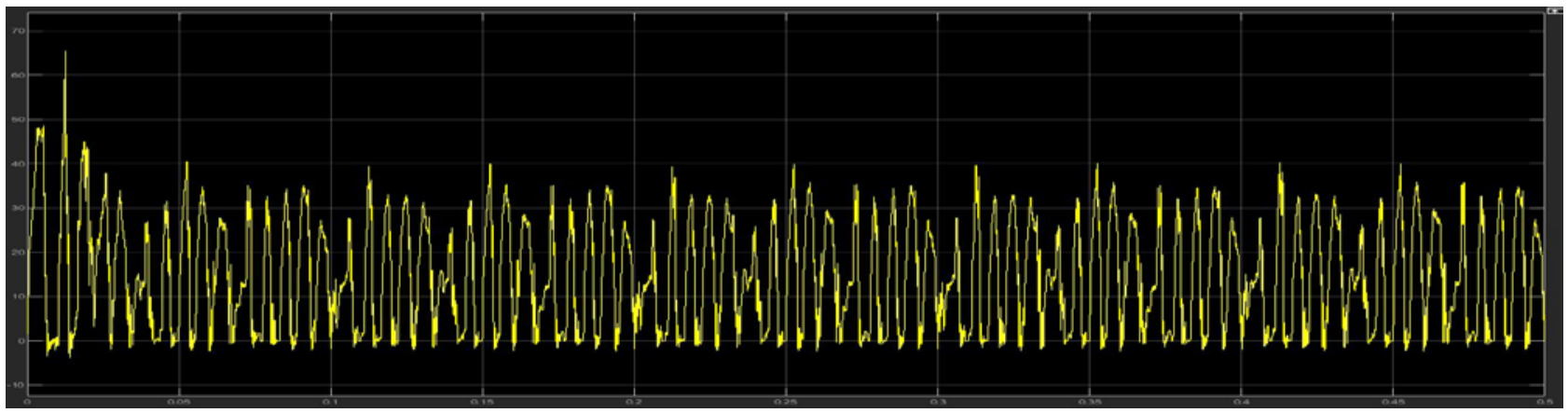

3) Rectifier current 


\section{IV.CONCLUSION}

Utilizing this composite line will more economical for development of new lines and will give advantage of included power with no adjustment in the current structure. The likelihood of transformation of existing AC line conductors into composite AC-DC line isexecuted in this paper utilizing MATLAB/Simulink. The theoretical results of the proposed system aretabulated in the table 1 and practical results are shown in fig2. The proposed ac-dc power flows yields better results compared to classical approaches.

\section{REFERENCES}

[1] H. .Rahman. B. H .Khan "Enhanced power transfer by simultaneous transmission of AC-DC a new FACTS concepts". In: IEE conference on Power Electronics, Machines and Drives (PEMD 2004),pp.186-191.

[2] H. .Rahman. B. H .Khan "Power Upgrading of Transmission Line by Combining AC-DC Transmission”.
IEEE Trans. On Power Systems, vol. 22. Pp 459-466J.

[3] H. .Rahman. B. H. Khan "Stability Improvement of Power System by simultaneous AC-DC Power Transmission" ELSEVIER. Electric Power System Research 78(2008) 756764.

[4] XinXing XU, NengLing Tai, "Scheme of simultaneous AC-DC Power Transmission in Medium Voltage Distribution Network” TENCON 20152015 IEEE Region 10 Conference Year:2015.

[5] P. S. Kundur, Power System Stability and Control. New York: McGraw-Hill, 1994.

[6] Azim Lotfjou ,Yong Fu“Hybrid AC/DC Transmission Expansion Planning," IEEE Trans. Power Syst. VOL.27, NO.3,JULY 2012

[7] E. W. Kimbark, Direct Current Transmission. New York: Wiley, 1971, vol. I. 